give false-negative results. Kubo et $a l^{4}$ found anti-HBc in $81 \%$ of over 200 sera from patients with hepatoma, though only $52 \%$ were $\mathrm{HBsAg}$-positive.

If hepatitis $\mathrm{B}$ virus causes hepatoma by initiating a chain of events in which active hepatitis leads to chronic hepatitis, cirrhosis, and eventually hepatoma then HBs-antigenaemia would be expected to be more common in hepatoma secondary to cirrhosis than in hepatoma unrelated to cirrhosis. This has in fact been found in most series. In a recent retrospective pathological study of hepatoma from California fewer than $1 \%$ of non-cirrhotic patients with hepatoma had markers of hepatitis B virus infection, whereas $73 \%$ of patients with cirrhosis had HBs antigenaemia. ${ }^{15}$ Admittedly, such a difference has not been found in major series from Britain and the United States. ${ }^{10} 16$

Susceptibility to hepatoma may be governed not only by risk of exposure to virus but also by the virulence of the virus, the tolerance of the host, the duration of infection, and nutritional and immunological factors. Various microtoxinsmost prominently aflatoxin, an aspergillus metabolite-have been implicated in cancer of the liver. ${ }^{17}$ There are geographical parallels between the incidence of hepatoma and both the frequency of hepatotoxins contaminating the diet and the prevalence of hepatitis B infection or carriage. This suggests cocarcinogenesis, with two factors necessary to produce the cancer. In some countries, such as Egypt, there is a high rate of hepatitis B infection but hepatoma is uncommon: failure to find evidence that aflatoxin is contaminating food in these countries would support the hypothesis.

Liver cancer, then, may result from chronic exposure to hepatocarcinogens, though it may also occur in an infected but otherwise normal liver. A hepatitis $\mathrm{B}$ virus vaccine given at an early age may be a means of preventing infection in endemic areas. Eliminating carriage of hepatitis $B$ virus in the normal population would then lead to fewer cases of hepatoma. The presence of $\mathrm{HBsAg}$ does not, however, prove that hepatitis $B$ virus causes the tumour, and other possibilities need to be considered. For example, the development of hepatocellular carcinoma might simply activate a latent hepatitis B virus, with production of surface or core antigen in infected cells. A recent survey of a normal Scottish population found that $7 \cdot 5 \%$ have anti-HBs antibody, suggesting latent or previous infection. ${ }^{18}$ Rates of latent infection may vary in different countries throughout the world. Alternatively, HBs-antigenaemia may indicate a defective immune response, resulting from insult by the same toxin that is responsible for hepatocarcinogenesis; thus aflatoxins have immunosuppressive actions. ${ }^{17} 19$

Finally, is HBs-antigenaemia in patients with hepatoma of prognostic importance and related to their clinical course? Recently Kubo et al $^{14}$ have confirmed earlier reports ${ }^{20}$ that the duration of chronic liver disease before hepatoma is detected is significantly shorter in HBsAg-positive than in HBsAgnegative patients (four years compared with six years). Survival after tumour detection, however, was not significantly related either to the presence of $\mathrm{HBsAg}$ or to the duration of the previous liver disease.

\footnotetext{
1 Ziegler, J L, et al, fournal of the National Cancer Institute, 1978, 60, 717.

2 Vogel, C L, et al, Lancet, 1970, 2, 621.

${ }^{3}$ Sherlock, S, et al, Lancet, 1970, 1, 1243.

4 Hadziyannis, S, et al, Lancet, 1970, 2, 100.

5 Tong, M J, et al, Annals of Internal Medicine, 1971, 75, 687.

${ }^{6} \mathrm{Kew}, \mathrm{M}$ C, et al, Cancer, 1974, 34, 539.

7 Theodoropoulis, G, Archimandritos, A, and Angelopoulos, B, Annals of Internal Medicine, 1975, 82, 809.

${ }^{8}$ Chainuvati, T, Viranuvatti, V, and Pongpipat, D, Gastroenterology, 1975,
} 68, 1261.
${ }^{9}$ Prince, A M, et al, International fournal of Cancer, 1975, 16, 376.

${ }^{10}$ Welsh, J D, et al, Gastroenterology, 1976, 70, 392.

11 Prince, A M, et al, Lancet, 1970, 2, 717.

12 Alpert, M E, and Isselbacher, K J, Lancet, 1971, 2, 1087.

${ }_{13}$ Maupas, P, et al, Lancet, 1975, 2, 69.

14 Kubo, Y, et al, Gastroenterology, 1978, 74, 578.

${ }_{15}$ Peters, R L, Afroudakis, A P, and Tatter, D, American fournal of Clinical Pathology, 1977, 68, 1.

${ }^{16}$ Johnson, P J, et al, Gut, 1978, in press.

17 Aleksandrowicz, J, et al, Przeglad Lekarsky, 1971, 28, 689.

18 Turbitt, M L, et al, fournal of Clinical Pathology, 1977, 30, 1124.

19 Savel, H, et al, Proceedings of the Society for Experimental Biology and Medicine, 1970, 134, 1112.

${ }^{20}$ Obata, H, et al, in Hepatic Scientific Memoranda H881. Buffalo, Calspan Corporation, 1975.

\section{Radioimmunoassay of serum prostatic acid phosphatase in prostatic cancer}

Earlier diagnosis of cancer of the prostate may become possible with the development of a radioimmunoassay for detection of the serum prostatic acid phosphatase. Biochemical estimation of the enzyme is in general use as an ancillary diagnostic procedure in suspected prostatic cancer and as an indicator of the response to treatment. Acid phosphatase is elaborated by adult prostatic acinar epithelium. When there is neoplastic proliferation, possibly with increased cellular permeability or other factors, more may be released into the circulation. The quantitative biochemical methods used to measure the concentration in the serum have been combined with refinements such as the 1-tartrate modification to exclude similar enzymes produced from other tissues or organs. Generally the results have given useful confirmation of the disease where there was local or metastatic spread but in earlier stages have proved less informative. Clinical experience has shown that values are significantly raised in only about a quarter of cases where the tumour remains confined to the prostate while $75 \%$ have raised values when there are metastases or extracapsular spread. This shortcoming may reflect the imprecision of the technique but is perhaps due to variations in the capacity of the neoplastic cells to sustain phosphatase production or to the defensive reaction of the tissues surrounding the tumour effectively limiting the entry of enzyme into the blood stream.

A new method of radioimmunoassay ${ }^{1}$ is probably more sensitive throughout the full range of pathological stages of the disease. The technique is complex: a specific antiserum is produced by the inoculation of female rabbits with purified acid phosphatase from adult human prostatic fluid; this is treated with suitably buffered bovine serum albumin and incubated with serum and ${ }^{125}$ I-labelled antigen for 45 hours. The percentage of labelled antigen bound to antibody is counted and the concentration of unknown prostatic acid phosphatase determined by reference to a standard curve.

From a preliminary trial of the technique in 600 normal men Foti and his colleagues ${ }^{1}$ showed that after puberty the level of the enzyme was little influenced by age. In a subsequent series of 50 normal controls (averaging 64.5 years) the values ranged between 3.5 and $6.6 \mathrm{ng}$ per $0.1 \mathrm{ml}$ serum. Using the upper limit as a guideline, they compared the results with those of standard enzyme assay in 113 patients with prostatic cancer and 187 controls with various diseases. The radioimmunoassay findings showed a significantly increased number of high values in the group with prostatic cancer which 
included many in the early stages of the disease. In 24 with stage I (clinically imperceptible) prostatic cancer high values of enzyme were detected in $12(50 \%)$ compared with $3(12 \%)$ using standard enzyme assay, while in 33 cases with stage II (palpable tumour confined within the gland) the corresponding ratio was $79 \%$ compared with $15 \%$. Nevertheless, raised values were also occasionally found in controls; some suffering from other forms of cancer, benign prostatic hyperplasia, and, surprisingly, after total prostatectomy. Many of these falsepositive results could be eliminated by raising the "cut-off" point of the test to $8.0 \mathrm{ng}$ per $0.1 \mathrm{ml}$ serum. With this modification, radioimmunoassay. remains considerably more accurate than standard enzyme assay.

The specificity and practical application of radioimmunoassay in diagnosing prostatic cancer may not be fully established yet, but the technique merits recognition. The raised values in other cancers, some patients with benign prostatic hyperplasia, and others who had previously undergone total prostatectomy suggests, however, that the method may not be entirely specific, possibly owing to the similarity of prostatic acid phosphatase to that from other sources. This has always been a problem with the biochemical tests; but one important difference may be that the radioimmunoassay must measure the immunological part of the molecule, which may not represent the biologically active part. Furthermore, though both techniques show more positive results with increasing spread of the disease, no relation has been established between phosphatase production and the malignancy of the tumour. As with any new screening test, only practical experience will show whether radioimmunoassay will prove to be of value to clinicians or whether it will remain of essentially academic interest.

${ }^{1}$ Foti, A G, et al, New England Fournal of Medicine, 1977, 297, 1357.

\section{Treatment of ankylosing spondylitis}

Most patients with ankylosing spondylitis never lose a day from work. In the past, misguided efforts to prevent spinal deformity encased victims in a plaster cast. The patients became inexorably bent, cracked the cast, and were left with fixed flexion deformities. We now know that this is the one rheumatic disease above all others that requires active exercises.

Yet, though the active approach is generally accepted, ${ }^{1-3}$ no formal clinical trial has ever evaluated such regimens. Clinicians at Bath (who are sufficiently interested to have sponsored the National Ankylosing Spondylitis Society) admit spondylitic patients for treatment and for intensive group physiotherapy in classes for three weeks. Other rheumatologists, with less cooperative patients, commonly organise a spondylitic clinic, where physiotherapists at regular intervals preach propaganda about exercises.

The Bath group found that 25 of 35 patients showed substantial improvement in neck movement with their regimen ${ }^{4}$ (lumbar spine lesions may cause more pain, but cervical spine changes cause more disability). Eleven patients seen three months after the course had improved further. The results of this interesting study raise many questions. Why did so many patients not respond? Were their spines already fixed and their condition irremediable? Why should they improve with regular exercise? Does exercise relieve pain and thus improve mobility-or was their analgesic regimen (not mentioned in the report) changed in hospital ?

For a condition with such a favourable natural course the doctor should limit treatment to agents that are not themselves worse than the disease. He must also emphasise the role of physical measures. The patient should sleep on a firm bed, with a pillow as small as possible. If he has a job in which he contorts himself for prolonged periods (for example, as a car mechanic), or if he is an assiduous clerk bent over his desk with never a moment to straighten his stiffening spine, then he should modify his pattern of work or find another occupation. He should avoid smoking, particularly to minimise the risk of chronic bronchitis, since he is likely to have severely restricted chest expansion.

The divided plaster bed, ${ }^{5}$ the halo splint, ${ }^{6}$ and skull traction ${ }^{7}$ have successfully reduced severe postural defects. Other appliances that may help patients with severe spondylitis include prismatic spectacles to extend a visual field limited by spinal rigidity and curvature; an adjustable mirror attached to the bed to give a better view of the surroundings; and a right-angled convex mirror device fixed to the car bonnet to improve vision to left and right, particularly at road junctions. ${ }^{2}$

Two of the best drugs for relieving pain and stiffness are indomethacin and phenylbutazone ${ }^{8}$ - and phenylbutazone may possibly modify the course of the disease. ${ }^{9}$ Flurbiprofen, ${ }^{10} 11$ sulindac, $^{3}$ and naproxen ${ }^{12}$ also have an effect. The most controversial form of treatment is radiotherapy. Physicians over 50 will testify to its effectiveness in many cases, but it has fallen almost totally into disuse because of the tenfold risk of leukaemia found in a large group of spondylitics so treated. ${ }^{13} 14$ Overall, however, this increased risk was small-certainly less than the risks of treatment with steroids. Indeed, the new edition of Davidson's Principles and Practice of Medicine ${ }^{15}$ still advocates the treatment in selected cases. The incidence of leukaemia after therapeutic or military radiation is related to the dose, ${ }^{16}$ and in a patient who does not respond to simple measures a single course of radiotherapy may well be the best treatment.

${ }^{1}$ Scott, J T, ed, Copeman's Textbook of Rheumatic Diseases, 5th edn. Edinburgh, Churchill Livingstone, 1978.

2 Wright, V, and Moll, J M H, Seronegative Polyarthritis, p 411. Amsterdam, North Holland Publishing Co, 1976.

${ }^{3}$ Calin, A, and Fries, J F, Ankylosing Spondylitis: Discussions in Patient Management. New York, Medical Examination Publishing Co, 1978.

${ }^{4}$ O'Driscoll, S L, Jayson, M I V, and Baddeley, H, Annals of the Rheumatic Diseases, 1978, 37, 64.

${ }^{5}$ Rose, G K, Rheumatism (London), 1961, 17, 63.

Perry, J and Nickel, V L, fournal of Bone and foint Surgery, 1959, 41A, 37.

Lee, M L H, Rheumatism (London), 1963, 19, 79.

${ }^{8}$ Godfrey, R G, et al, Arthritis and Rheumatism, 1972, 15, 110.

9 Boersma, J W, Scandinavian Fournal of Rheumatology, 1976, 5, 60.

10 Calin, A, and Grahame, R, British Medical fournal, 1974, 4, 496.

11 Sturrock, R D, and Hart, F D, Annals of the Rheumatic Diseases, 1974, 33, 129.

12 Hill, H F H, and Hill, A G S, Scandinavian fournal of Rheumatology, 1973, suppl 2, 121 .

13 Court Brown, W M, and Abbatt, J D, Lancet, 1955, 1, 1283.

${ }^{14}$ Court Brown, W M, and Doll, R, British Medical fournal, 1965, 2, 1327.

${ }^{15}$ Duthie, J J R, and McCormick, J N, Davidson's Principles and Practice of Medicine, 12th edn, ed J Macleod, $p$ 636. Edinburgh, Churchill Livingstone, 1977.

${ }^{16}$ Spiers, F W, Radioisotopes in the Human Body-Physical and Biological Aspects, p 236. New York and London, Academic Press, 1968. 